\title{
Aqui Jaz o Amor: 0 nascimento do homem, a produção das masculinidades e as relações internacionais
}

\author{
Here Lies Love: The birth of man, the production of masculinities and the \\ international relations
}

\author{
Diego Santos Vieira de Jesus \\ Pontifícia Universidade Católica do Rio de Janeiro \\ dsvj1408@terra.com.br
}

\begin{abstract}
Resumo
O objetivo central é examinar como fenômenos sociopolíticos, econômicos e culturais no nível internacional atuam no processo de constituição das masculinidades ocidentais, bem como tais masculinidades constroem o sentido das relações de poder articuladas na política entre Estados e demais atores no nível externo. $\mathrm{O}$ argumento central aponta que fenômenos como a guerra, a expansão da ordem internacional e a globalização podem reforçar mecanismos de segregação e de hierarquização da diferença ao criarem discursos e valores que legitimam as masculinidades hegemônicas à custa das feminilidades e das masculinidades subordinadas e permitirem o acesso a recursos materiais importantes à perpetuação das masculinidades hegemônicas, mesmo que por vezes haja mais espaço para a expressão de desafios e concepções alternativas a elas. Simultaneamente, a consolidação das masculinidades hegemônicas entrelaça-se a outras formas de dominação e de exclusão de forma a perpetuar a homogeneidade, a coesão e a integridade de comunidades políticas específicas no Ocidente e reificar hierarquias e estratégias espaciais e temporais de marginalização da diferença. Porém, o resgate do amor pode oferecer respostas aos desafios da interação com a diversidade por meio da construção de confiança, da autorreflexão crítica, do diálogo e da aliança entre críticas sociais culturalmente diversas à desigualdade.
\end{abstract}

Palavras - chave: Masculinidades; Relações Internacionais; guerra; globalização; ordem internacional.

\begin{abstract}
The aim is to examine how sociopolitical, economic and cultural phenomena in the international level work in the constitution of Western masculinities, and how such masculinities construct the meaning of power relations articulated in the politics among states and other actors in the external level. The central argument indicates that phenomena such as war, the expansion of international order and globalization can enhance the mechanisms of segregation of difference in creating discourses and values that legitimize hegemonic masculinity at the expense of femininities and subordinate masculinities and allow access to material resources that are important to the perpetuation of hegemonic masculinities, even though sometimes there is room for the expression of alternative concepts and challenges to them. Simultaneously, the consolidation of the hegemonic masculinities is interconnected with other forms of domination and exclusion in order to perpetuate the homogeneity, cohesion and integrity of specific political communities in the West and reify hierarchies and spatiotemporal strategies of marginalization of difference. However, love can provide answers to the challenges of the interaction with diversity by building confidence, critical self-reflection, dialogue and alliance among culturally diverse social criticism to inequality.
\end{abstract}

Keywords: Masculinities; International Relations; war; globalization; international order. 


\section{Introdução}

A construção das noções de masculinidade e o desenvolvimento de hierarquias delas em relação às feminilidades e entre as próprias masculinidades são processos fluidos e dinâmicos que variam espaçotemporalmente Revelam, assim, que estratégias de dominação e controle operam de maneira múltipla em cada circunstância específica. Numa visão mais abrangente, as oposições entre 'masculino' e 'feminino' constituem binarismos poderosos numa lógica logocêntrica que perpassa a filosofia e a cultura ocidental moderna, e, nesse processo, a masculinidade é predominantemente equacionada à atividade e à vitória, enquanto a feminilidade é associada à passividade e à derrota. A lógica falocêntrica que marginaliza o feminino define o masculino a partir da relação entre esses pares: a valorização do masculino dá-se com a concepção do feminino como categoria residual em oposição à qual o masculino se define e é gradativamente naturalizada e apresentada em termos absolutos, não-problematizados ou dados. Essas dicotomias ajudam a construir desigualdades constitutivas da vida social e camuflam relações mais complexas no tecido social. Com um olhar mais preciso sobre o conceito de 'masculinidade', vê-se que ele é plural e se percebe que as 'masculinidades hegemônicas' no Ocidente - que se referem a modelos dominantes de masculinidade, em geral heterossexual e branca - são construídas não apenas em oposição às feminilidades, mas a partir da estigmatização das 'masculinidades subordinadas' que se diferenciam dela, como as homossexuais. Ademais, em diversos momentos da história do sistema internacional, tais masculinidades hegemônicas ocidentais assumiram um perfil etnocêntrico, conduzindo hierarquias globais que institucionalizavam a marginalização de masculinidades não-brancas, não-ocidentais e nãocapitalistas (HOOPER, 2001, p.43-45, 54-55).

As masculinidades hegemônicas são modelos públicos, simplificados e idealizados de aspectos simbólicos da interação. Como existem disputas e negociações em cada circunstância específica sobre os elementos que a constituem dentre um conjunto de características possíveis e disponíveis, nota-se que elas são plásticas enquanto veículos de preservação de associações entre masculinidade e poder sob circunstâncias sociopolíticas, econômicas e culturais variáveis e se transformam para constituir traços que preencham as necessidades estratégicas de conquista e de manutenção do poder. Embora muitas dessas características disponíveis em diferentes tempos e culturas possam ser contraditórias entre elas, elas podem ser reunidas em diferentes combinações e mobilizadas simultaneamente na busca de diferentes fins, de forma que até mesmo elementos de masculinidades subordinadas passadas e presentes podem ser assimilados a fim de revigorar as hegemônicas, e as características prévias dessas masculinidades podem ser abandonadas e posteriormente recuperadas de acordo com as circunstâncias. Num momento em que o poder das masculinidades hegemônicas pauta-se na flexibilidade em relação à caracterização monológica que ela faz das subordinadas, as qualidades e as práticas que definem os conteúdos das masculinidades são, assim, uma questão política sujeita a disputas e negociações heterogêneas de poder em múltiplos níveis sociais, inclusive o internacional (HOOPER, 2001, p.56, 60$62,75-76)$.

A dimensão internacional pode ter um papel significativo na produção de identidades - inclusive as de gênero, como as masculinidades. Nesse caso específico, as identidades masculinas são também resultados da participação desses homens nos eventos político-sociais, econômicos e culturais no nível externo. Todavia, a discussão sobre a construção das masculinidades pelas relações internacionais ainda é um tema subexplorado. Tendo isso em vista, o objetivo central deste artigo é examinar como fenômenos sociopolíticos, econômicos e culturais no nível internacional atuam no processo de constituição das masculinidades ocidentais, bem como tais masculinidades constroem o sentido das relações de poder articuladas na política entre Estados e demais atores no nível externo. $\mathrm{O}$ argumento central que pretendo defender aponta que fenômenos como a guerra, a expansão da ordem internacional - entendida aqui como uma série de arranjos estabelecidos entre atores no nível externo que definem suas relações com os outros e as expectativas mútuas sobre sua interação (IKENBERRY, 2000) - e a globalização podem reforçar mecanismos de segregação e de hierarquização da diferença ao criarem discursos e valores que legitimam as masculinidades hegemônicas à custa das feminilidades e das masculinidades subordinadas e permitirem o acesso a recursos materiais importantes à perpetuação das masculinidades hegemônicas, mesmo que, por vezes, haja espaço para a expressão de desafios e concepções alternativas a elas. Simultaneamente, a consolidação das masculinidades hegemônicas entrelaça-se a outras formas de dominação e de exclusão de forma a perpetuar a homogeneidade, a coesão e a integridade de comunidades políticas específicas no Ocidente e reificar hierarquias e estratégias espaciais e temporais de marginalização da diferença, seja do feminino, seja 
dos entendimentos cultural e temporalmente distintos do próprio conceito de masculinidade. Porém, o resgate do amor pode oferecer respostas aos desafios da interação com a diversidade por meio da construção de confiança, da autorreflexão crítica, do diálogo sobre experiências e críticas à opressão e à exclusão visando à sua superação no pensamento e na prática e da aliança entre críticas sociais culturalmente diversas à desigualdade. Na próxima seção, examinarei como a guerra e os desenvolvimentos na área militar e as masculinidades constituem-se mutuamente. Nas duas seguintes, farei o mesmo com relação a expansão da ordem internacional e a globalização, respectivamente. Nas considerações finais, examinarei como o amor pode reconstruir masculinidades ocidentais a partir de confiança, intimidade e dialogo.

\section{A guerra, a dimensão militar e a produção das masculinidades}

O confronto militar e a guerra são fenômenos que exemplificam a forma como as relações internacionais produzem masculinidades. A guerra teve papel fundamental na definição do que significa ser 'homem', tanto em nível simbólico e institucional como na definição do corpo masculino. Na dimensão simbólica, a ideia de que os homens tiram a vida enquanto as mulheres a dão reifica as diferenciações entre esses pares e, no aparato de guerra moderno, reforçou as masculinidades dos soldados e a exclusão das mulheres da situação de combate. A guerra é concebida, assim, como uma expressão completa da 'agressão natural' do homem, bem como da sua urgência em proteger seu país e suas 'mulheres' (HOOPER, 2001, p.81-83). Nos Estados-nação modernos, as Forças Armadas são concebidas como 'escolas para a nação' que criam um ideal de 'masculinidade nacional'. A dureza e o sacrifício são incorporados pelos militares, de forma a fazer com que os ideais masculinos hegemônicos de coragem e bravura tornem-se o conteúdo do caráter do 'cidadão-soldado', defendam-se as honras pessoal e patriótica a fim de se evitar a vergonha e se criem narrativas culturais e pessoais de incorporação de masculinidades militares pautadas na força nacional e na determinação (NYE, 2007, p.421-423). Além de o serviço militar servir como um rito de passagem para que 'meninos' se tornem 'homens' ao longo da era moderna, o treinamento envolve a modelagem física e social do corpo do homem, disciplinando-o, definindo seu estilo de masculinidade e seus contornos físicos e ampliando a vigilância e a regulação sobre ele ao torná-lo 'economicamente eficiente' e promover o autocontrole emocional (HOPPER, 2001, p.81-83). O corpo e outras representações e acessórios relacionados ao universo militar - tais quais uniformes concebidos como extensões do 'corpo militarizado' do homem e armas que trazem a idealização simbólica e real da agressão - representam regiões em que as identidades masculinas - especialmente as hegemônicas - são praticadas e construídas nessa instituição. Explicita-se como o corpo é colocado numa posição central nas performances sociais sobre o que é ser não só um militar, mas um homem (MANKAYI, 2008, p.24).

Segundo Hinojosa (2010, p.179-181), as masculinidades hegemônicas estão no topo da hierarquia de gênero e existem em relação às construções subordinadas. As características mais tradicionais incluem a tomada de riscos, a autodisciplina, a dureza física, o desenvolvimento muscular e o desejo abertamente heterossexual, sendo que tais elementos são colocados em posições de domínio simbólico. Muitos homens aderem ao serviço militar por conta do histórico familiar e das considerações econômicas. Além disso, o serviço militar permite o acesso a recursos materiais importantes à masculinidade hegemônica, como a segurança econômica e corpos fisicamente definidos e capazes oferecidos pelo treinamento. No caso de Estados em posições relativas superiores na distribuição de poder nos sistemas regional e multilateral, cabe destacar que, como as identidades como as masculinidades são construídas a partir de interação entre recursos materiais e simbólicos disponíveis, as Forças Armadas tornam alguns desses recursos institucionalmente disponíveis no que diz respeito à construção de masculinidades hegemônicas, atribuindo juridicamente a tais homens o direito de usar a força letal para a manutenção da dominação política e física de outros indivíduos e Estados. No processo de definição das masculinidades dos homens soldados a partir da oposição a outros indivíduos como os homens civis e as mulheres -, as narrativas enfatizam a centralidade do corpo ou a representação física, também evidentes em performances normativas fora do ambiente militar. Como Mankayi (2008, p.24$25,32,39-40)$ argumenta a não-conformidade ao físico ideal masculino é apresentada como superável, uma vez que o homem se torne um soldado. Num momento em que os termos da masculinidade requerem que os homens tenham um nível elevado de força muscular, o treinamento físico promovido pelo aparato militar pode permitir que eles sejam fisicamente definidos. De maneira semelhante à forma como o corpo funciona como chave na construção de uma masculinidade 'bem sucedida', o uniforme e o aparato militares servem como evidência dessa masculinidade, o que tem uma 
função discursiva nas construções das masculinidades hegemônicas e da própria identidade militar. Ademais, o aparato militar incorpora um código de honra que define uma série de virtudes supostamente masculinas, como a bravura, o risco, a honra, a coragem, o espírito aventureiro e o heroísmo, e reflete ideais masculinos no Ocidente, como a liberdade e a fraternidade. $\mathrm{Na}$ construção da 'maturidade emocional' dos membros das Forças Armadas, a admissão da vulnerabilidade emocional não é tolerada em face de seu potencial de ameaça ao moral militar.

Trabalhando esse processo de construção social de forma mais detalhada, o corpo masculino é concebido como 'seco', 'limpo', 'ereto' e 'rijo', mas sempre sujeito à contaminação pela 'sujeira' feminina, cujos corpos são tratados como 'abertos', 'selvagens' e 'promíscuos' e ameaçadores da 'integridade masculina' em face do desejo que provoca no homem soldado heterossexual. Nesse sentido, a violência física contra a mulher tornou-se parte integral da constituição do modelo hegemônico de masculinidade do corpo militar de diversos Estados ao longo da história. Além disso, os 'homens que não lutam' são depreciados por não correrem alto risco de morte ou de prejuízo físico, e as próprias políticas de recrutamento ajudaram a definir modelos hegemônicos e subordinados de masculinidade. Em diversos países, grupos subordinados étnica ou religiosamente e/ou homossexuais masculinos foram barrados do serviço militar ou foram limitados a papeis restritos com base em ideologias de 'segurança nacional', num contexto em que os direitos plenos à cidadania foram conferidos apenas àqueles homens que participam da defesa do Estado (HOPPER, 2001, p.81-84). Nessa perspectiva, a própria estrutura externa das masculinidades hegemônicas garante que mulheres sejam excluídas da participação direta em combate e a política oficial permite aos homens manter posições de dominação sobre as mulheres. Na dimensão interna, a estrutura hierárquica das masculinidades viabiliza que algumas construções sejam dominantes e privilegiadas em relação a outras: enquanto as masculinidades hegemônicas brancas e ocidentais estão no topo da hierarquia e recebem a maior parte dos dividendos patriarcais, as subordinadas - em geral representadas pelas masculinidades imigrantes, negras ou gays - são oprimidas, exploradas e sujeitas ao controle pelas formas dominantes e são barradas pelo poder socioeconômico e ideológico em muitas sociedades ocidentais (HINOJOSA, 2010, p.180-181).

Tal obstáculo é colocado em diversos países, pois, como colocam Britton \& Williams (1995, p.2-5) ao examinarem especificamente a situação com relação aos homossexuais masculinos nas Forças Armadas dos
EUA na década de 1990, a presença de gays é percebida por setores militares mais conservadores como uma ameaça ao desempenho efetivo individual e coletivo. $\mathrm{Na}$ visão de tais setores, homossexuais seriam alvos de assédio pelos soldados heterossexuais e não imporiam respeito se estivessem em posições de comando. O preconceito social ofereceria sustentação a essa posição: sob tal perspectiva, a marginalização de homossexuais nas Forças Armadas devia-se à necessidade de não 'ofender' a população, que vê a homossexualidade de forma negativa. De forma ainda mais densa, Britton \& Williams (1995, p.2, 11-15) defendem que a resistência à maior participação de mulheres e de homens homossexuais reflete $o$ privilégio institucional da heterossexualidade masculina nas Forças Armadas, cujas regras se assentam no apoio à família tradicional e no desenvolvimento de uma 'heterossexualidade compulsória' por meio do uso de força, sanções e controle da consciência. Assim, a heterossexualidade que caracteriza os modelos hegemônicos de masculinidade nas Forças Armadas é uma instituição política com bases materiais e ideológicas, que tolera, por exemplo, a objetificação e a exploração da mulher e a glorificação da violência em diversas regiões do planeta, mas que receia que a homossexualidade masculina possa interferir na 'ordem' e na 'disciplina'. Na prática, a exclusão ou a marginalização de homens homossexuais no contexto de consolidação das masculinidades hegemônicas nos meios militares visava à supressão de elementos homoeróticos nos vínculos de amizade, camaradagem e solidariedade entre os soldados - concebidos como essenciais a fim de se evitarem disputas internas entre as unidades das Forças Armadas - e outros fatores altamente sexualizados da vida militar. Assim, a conquista da disciplina e da eficiência dá-se por meio de uma confluência de elementos privilegiados pelas masculinidades hegemônicas como a bravura e a heterossexualidade e, sinais de fraqueza, sensibilidade ou vulnerabilidade - interpretados como homossexualidade e sinônimos de 'masculinidade fracassada', nesse contexto, são suprimidos (BRITTON \& WILLIAMs, 1995, p.11-15).

\section{A expansão colonial, imperialista e imperial da ordem internacional e a produção das masculinidades}

O processo de expansão da ordem internacional teve papel fundamental na construção dos significados das masculinidades hegemônicas no Ocidente, bem como das subalternas. Simultaneamente, tais 
significados também constituíram os contornos desse processo, em particular reforçando mecanismos de segregação e de hierarquização da diferença. Além de se reforçarem estratégias 'temporais' de emprego das noções de desenvolvimento e modernização - que cristalizam a diferença como 'atraso' -, a operação dos referenciais das masculinidades hegemônicas também consolidou estratégias 'espaciais' de segmentação. A articulação simultânea de tais estratégias naturalizou as delimitações espaciais de dentro / fora e essencializou a sequência de tradição / modernidade, espacializando o tempo e situando a diferença ao longo do espaço em 'estágios de desenvolvimento'. Os objetivos eram a constituição de uma uniformidade relativa dos sistemas políticos no processo de expansão da ordem internacional e o desenvolvimento de esquemas classificatórios espaçotemporais hierarquizantes e disciplinadores que concebiam a diferença como elemento desestabilizador da harmonia interna. Ao se tratarem modelos específicos de masculinidade hegemônica como 'naturais' ou 'dados' a determinadas sociedades, tentou-se gerenciar a diferença a partir de sua feminização e depreciação com erradicação, assimilação ou expulsão na 'cruzada interna' pela unidade da comunidade política estatal. Tal resposta hierarquizante e disciplinadora a diferença transbordou para seu tratamento na esfera externa, figurando-se essa diferença como uma ameaça constante interditada nas fronteiras, enfrentada militarmente ou colonizada. Isso, em diversos casos, desembocou na operação de um processo de homogeneização cultural sistemática acompanhado da constituição uniformizadora das unidades políticas (BLANEY \& INAYATULLAH, 2004, p.44-45). Tal processo tornou-se visível em alguns momentos de expansão da ordem internacional, como no colonialismo dos séculos XVI e XVII, na expansão imperialista no século XIX e no transbordamento do espaço político imperial norteamericano nos séculos XX e XXI.

Tanto a produção intelectual dos séculos XVI e XVII como as práticas políticas resultantes desse pensamento no nível internacional apontavam para um processo de preservação e de cristalização da integridade do 'império da uniformidade' doméstico nos principais Estados nacionais modernos em formação na Europa naquele contexto. Em face das guerras religiosas na Europa e dos desafios na incorporação dos ameríndios às visões de mundo europeias, o legado intelectual naturalizava a diferença como elemento desestabilizador da associação política unificada e harmoniosa. Pensadores modernos inseridos em empreendimentos de pacificação buscavam fundações não-questionáveis da autoridade soberana e desproviam o 'estado de natureza' da riqueza da sociedade civil ${ }^{1}$. A classificação dos ameríndios num estágio pré-social associado à desordem - o 'estado de natureza' - procurava resguardar a precária noção de 'superioridade cultural' europeia e fortalecer a justificativa de práticas coloniais (BLANEY \& INAYATULLAH, 2004, p.3543). Naquele contexto, a masculinidade do colonizador - associada à bravura na conquista de terras fora do continente europeu e a força na imposição de sistemas político-sociais europeus aos nativos na América naquele contexto - pressupunha a negação do feminino interior, a marginalização do discurso do Outro - em particular referente ao ameríndio - e a cristalização de uma concepção autorreferencial do exercício do poder. Era, ao mesmo tempo, peça fundamental na construção de um empreendimento baseado no desenvolvimento de estratégias de dominação político-cultural da população local (DARBY, 1998). A masculinidade do europeu alimentava a violência na atividade colonizadora e oferecia sustentação à ideia de superioridade militar do colonizador, que concebia os nativos como fracos e incapazes. O desenvolvimento de um aparato de produção econômica voltado para atender às necessidades metropolitanas - vista pelo colonizador como mais dinâmica e forte que a local - conduzira à gradativa desorganização da produção ameríndia, enquanto o controle da sexualidade das mulheres pelo Estado e pela Igreja construía um tecido social colonial que criava condições de possibilidade para o fortalecimento do domínio masculino sobre a sociedade, particularmente no que dizia respeito ao direcionamento moral e religioso nas relações entre homens e mulheres e a associação dessas normas sociais com as assimetrias sociopolíticas em múltiplas áreas entre os colonizadores e os ameríndios. Naquela organização social, tais nativos eram submetidos a trabalhos forçados, enquanto as mulheres indígenas exerciam diversos serviços pessoais - inclusive sexuais - aos colonizadores (STOLCKE, 2006).

$\mathrm{O}$ empreendimento que resulta da interseção da masculinidade dominante do colonizador europeu com as ideias de superioridade racial e as assimetrias de classe social conduziu, como lembra Stolcke (2006), a novos sistemas de identificação social no mundo colonial. $\mathrm{O}$ efeito foi uma hierarquia sustentada numa interpretação linear da história - que acomodava o ameríndio no 'estado de natureza', num tempo distinto dos europeus -, intimamente ligada à prática política que reproduzia a força e a superioridade militar do colonizador e conduzia à crescente desorganização da produção local. Ampliando o escopo desse argumento, a concepção universal de 'estado de natureza' criou condições para ordenação de culturas em 'estágios de 
desenvolvimento', oferecendo sustentação para abordagens sobre relações desiguais entre comunidades políticas. $\mathrm{Na}$ expansão imperialista do século XIX, novas hierarquias são construídas, em particular aquelas girando em torno do conceito de 'civilização', entendido por John Stuart Mill como desenvolvimento material em termos de progresso econômico e tecnológico e moral na forma de 'bons governos' baseados em sistemas políticos e jurídicos justos e eficientes (KEENE, 2002, p.112). Naquele contexto, os objetivos da expansão imperialista inserida numa nova fase do capitalismo marcada pela fusão do capital bancário e do capital industrial - eram o reinvestimento do capital acumulado, já que o espaço nos limites do Estado-nação não era suficiente para a reprodução do capital, bem como a busca de novos mercados consumidores, a necessidade de controlar regiões produtoras de matérias-primas essenciais à indústria, a necessidade de dirigir excedentes populacionais para outras áreas não-europeias, a conquista de pontos estratégicos para a defesa de colônias já conquistadas e a missão 'civilizadora' de povos considerados 'atrasados' (JOLL, 1976).

A estigmatização do não-europeu como 'selvagem' ou 'bárbaro' que deveria ser convertido ao padrão civilizacional europeu solucionou o dilema de interação com a diferença ao traduzi-la como inferioridade (WALKER, 2005, p.2): a diversidade era objetificada e disciplinada, visando-se a preservar a coesão da identidade dos Estados europeus conquistadores. Naquele contexto, a masculinidade europeia vinha associada de forma ainda mais complexa ao discurso de superioridade racial, que justificava a missão civilizatória: a própria produção de conhecimento nesse momento aponta para um raciocínio utilitarista que transforma o saber sobre o outro em conhecimento para dominação. O empreendimento geopolítico resultante dividiu África, Ásia e Oceania em zonas de neocolonização europeia, implicando o uso instrumental da violência a serviço de interesses econômicos das burguesias das metrópoles. Porém, ao apontar que os encontros coloniais a época da expansão imperialista no século XIX também envolviam a ambivalência do colonizador e do colonizado e que podiam existir momentos de cumplicidade com a diferença localizada dentro e fora, Darby (1998) argumenta que as narrativas ficcionais sobre a conquista imperialista evidenciam a vulnerabilidade e a transitoriedade da supremacia ocidental - inclusive no que dizia respeito as questões de gênero - e salientam contramovimentos que introduzem intercursos entre o moderno e o tradicional que não estavam encapsulados em antagonismos recíprocos. Desvela-se, assim, que as linhas divisórias que conduziam à dominação sustentada pela masculinidade europeia e ao absolutismo moral na rejeição de outros povos eram traçadas parcialmente pela insegurança e pelo desejo em relação ao outro pelos seus elementos de diferença e sua similaridade com tempos passados. As inclinações masculinas dos textos acerca da intervenção europeia na Ásia e na África são permeadas por homoerotismo e a concepção ameaçadora da mulher, os quais captam a dificuldade no tratamento da diferença e representam desafios a estrutura de poder imperial e subversões as noções baseadas nas masculinidades hegemônicas daquela época, explicitando-se sua vulnerabilidade.

No mundo contemporâneo, em face da necessidade de disciplinar organizações terroristas e Estados que as patrocinam e supostamente buscam desenvolver armas de destruição em massa, o maleável conceito de 'civilização' reafirma a defesa de avanço socioeconômico, 'bom governo' e direitos humanos e se adapta fortalecendo valores democráticos e o repúdio ao terrorismo e incorporando o combate à proliferação de tais sistemas num contexto de redefinição dos limites da vida política nas formas do 'global' e do 'imperial'. O transbordamento do espaço político no qual se exerce a autoridade soberana para além das fronteiras do Estado provocou a desestabilização da demarcação entre as esferas doméstica e internacional; todavia, tal transformação de fronteiras não pressupôs a sua superação enquanto ideal regulador: os limites artificialmente determinados mostram-se flexíveis a ponto de ainda definirem a autoridade sobre o espaço e traçarem antagonismos, mesmo que essas fronteiras não permaneçam onde estavam até então. A dicotomia 'civilizados / bárbaros' operou simultaneamente a outras hierarquias baseadas em noções de gênero que atuaram no processo de constituição da identidade norte-americana. Na guerra no Iraque em 2003, por exemplo, as imagens de Bush como um corajoso cowboy e a Europa como 'covarde' e 'fraca' foram defendidas em diversos meios políticos e de comunicação de forma a simbolicamente mobilizarem a noção de masculinidades hegemônicas ligadas à violência e ao heroísmo no contexto de justificação e de condução da ação militar dos EUA e desvalorizar a posição dos críticos a partir da feminização do continente europeu. Na imagem do cowboy - dotada de força e de bravura -, observa-se a interação entre as hierarquias estabelecidas no contexto da guerra: além de representar a coragem e o sentido masculinizante de aventura ligada à cultura e ao nacionalismo norteamericanos, o cowboy também representa o poder da 'civilização' contra forças 'selvagens' e 'fora-da-lei' que 
trariam desordem - no imaginário norte-americano, os nativos indígenas do Oeste. Dentro do que se entende como essa 'civilização', opera simultaneamente outra dicotomia: enquanto o cowboy representa o lado mais rústico, independente e livre do Oeste norte-americano, a Europa aparece como o Leste hiper-refinado e educado, mas 'afeminado' e frágil (CHRISTENSEN \& FERREE, 2008, p.287-288). Simultaneamente, operam outras hierarquias que reificam a posição superior das masculinidades hegemônicas brancas norte-americanas e marginalizam outras masculinidades subordinadas em posições inferiores: terroristas ou membros de sociedades de países rotulados como 'párias' são enquadrados em categorias inferiores de desenvolvimento ou mesmo 'primitivos', dotados, assim, de uma hiper masculinidade que os limita a corpos que não são repositórios da razão ou do espírito como aqueles da masculinidade branca norteamericana, 'racional' e 'sensata'. Em vez de feminilizadas como outras masculinidades subordinadas, as masculinidades dos 'párias' são animalizadas e rotuladas como patologicamente 'hiper masculinas'. Observa-se, assim, a interpenetração entre hierarquias de gênero e civilizacionais, o que permite múltiplas permutações e nuances na construção da superioridade das masculinidades hegemônicas.

É possível identificar que, em torno de símbolos como o cowboy, formam-se sistemas complexos de referência que trazem significados às relações de poder (CHRISTENSEN \& FERREE (2008, p.288). A evocação da noção de gênero carrega conotações de força e fraqueza, que reforçam não apenas hierarquias entre norte-americanos 'fortes e destemidos na missão de levar a civilização a outras partes do mundo' e iraquianos 'bárbaros, atrasados e disfuncionais', mas também, dentro da própria 'civilização ocidental e liberal', entre americanos 'másculos e bravos' e europeus 'afeminados e covardes'. Como lembram Christensen \& Ferree (2008, p.288), a decisão de usar a força militar por um Estado é uma expressão extrema de seu poder, de forma que o debate sobre a entrada e a condução de uma guerra é um fórum excelente para que conotações de gênero e poder operem simbolicamente. Assim, desde os atentados de 11 de setembro de 2001, o discurso em torno não somente do terrorismo mas dos Estados-pária mostrou-se organizado em binarismos - 'racional' / 'irracional', 'dominador / dominado' etc. -, e as questões de gênero vieram alimentar - e até mesmo exagerar - tais segregações como arquétipos, estruturando opções políticas e trazendo obstáculos para negociações e resolução de conflitos de valores e posições (CHRISTENSEN \& FERREE, 2008, p.288).

A defesa de uma noção dominante de masculinidade ligada à violência e ao heroísmo presente na imagem do cowboy - leva à rotulação de outras masculinidades como resultados de processos de 'afeminação' incompatíveis com os do grupo identificado com as masculinidades hegemônicas. Tais masculinidades alternativas - como as desenvolvidas na Europa - representam desafios à masculinidade hegemônica como um padrão humano, bem como às relações institucionais que sustentam tal hegemonia. Essas diferentes concepções são, conforme lembram Christensen \& Ferree (2008, p.290), manipuladas e empregadas nos círculos políticos a fim de estruturar o debate e definir vantagens a alguém. $\mathrm{O}$ que defendo é que, no caso da guerra do Iraque em 2003, a operação do conceito de masculinidade hegemônica ligada à violência e ao heroísmo deu-se a partir da condenação de outras masculinidades desenvolvidas não somente na Europa, mas também nos próprios EUA, que pudessem sinalizar moderação, medo, vulnerabilidade ou fraqueza ao lidar com o Iraque. A postura dura pautada na utilização da violência pela administração Bush atendia à necessidade de preservar e fortalecer a coesão e a integridade da identidade norte-americana em face do enfrentamento de ameaças externas no novo contexto internacional. Assim, representações alternativas à masculinidade hegemônica personificada na imagem do cowboy - como as masculinidades europeias baseadas na diplomacia e na moderação - e às narrativas de heroísmo de soldados norteamericanos nos campos de batalha foram depreciadas e associadas à fraqueza e à feminilidade, enquanto Bush e sua equipe - identificados com o heroísmo do cowboy - eram revestidos da responsabilidade de disciplinar aqueles que prejudicassem a estabilidade da 'tradicional família norte-americana'.

Com a mobilização de apoio às medidas de segurança nacional e internacional a partir das hierarquias, concepções do que seriam um 'bom homem' e um 'mau homem', bem como de uma 'boa mulher' e de uma 'má mulher', são evocadas numa lógica de 'proteção masculina': um 'bom homem' se arrisca para proteger seus dependentes dos 'homens maus', vistos como 'cruéis' e 'bárbaros', enquanto as 'boas mulheres' aceitam essa proteção e honram seus protetores, e as 'más mulheres' desafiam e rejeitam a proteção. Nessa narrativa, enquanto terroristas e Estados-pária são associados a 'maus homens', países europeus que se opuseram a ação norte-americana no Iraque - como a França e a Alemanha - são associados as 'más mulheres' e, assim, desvalorizados, masculinizados no sentido hegemônico como 'frescos' ou 'covardes' e rotulados como 'ingratos' pela proteção conferida pelos Estados Unidos. A figura do cowboy, assim, silencia masculinidades desafiantes, pois 
carrega consigo a dureza e a bravura, que se aventura por um 'território desconhecido' com 'coragem e glória'. Transcendendo tal concepção, ela ainda representa a expansão das fronteiras da 'civilização' a partir da força das armas. Isso permitiu que a relação com o Iraque se tornasse ainda mais bruta e a interação com a Europa se reduzisse a um binarismo entre as masculinidades hegemônicas do cowboy - que silenciou masculinidades alternativas até mesmo nos próprios Estados Unidos - e as suas formas alternativas ligadas ao cavalheirismo e à negociação, desenvolvidas em grande parte dos países europeus que se opuseram à guerra do Iraque. A Europa, assim, é masculinizada no sentido dominante do termo e representada não somente como uma 'mulher', mas uma mulher 'má' e 'ingrata' em um 'casamento' ou um 'romance', no qual cabe ao 'homem' - dotado de força e poder - a prerrogativa de tomar as decisões. É evidente que essa visão hegemônica de masculinidade como poderosa, heterossexual e decisiva foi contestada em diversas partes do mundo, inclusive por boa parte da população norte-americana. Porém, nos meios de comunicação e nos meios políticos, tais imagens ligadas a uma masculinidade hegemônica vinculada a violência e ao heroísmo tiveram papel fundamental na construção da coesão da identidade norte-americana e na perpetuação de um entendimento depreciativo da diferença, fosse o Iraque, fossem os europeus que discordaram da ação norte-americana (CHRISTENSEN \& FERREE, 2008, p.293-298, 301).

\section{A globalização e a produção das masculinidades}

Outro fenômeno inserido no contexto das relações internacionais contemporâneas e que atua no processo de construção das masculinidades ocidentais é a globalização. Ela pode ser vista como um conjunto de processos que modificaram a forma espacial de organização humana para padrões transcontinentais e inter-regionais de atividade, de interação e de exercício de poder. Tal conjunto não é uma condição singular ou um processo linear; em vez disso, é um fenômeno multidimensional que envolve domínios de atividades e de interação que incluem a esfera econômica, a política, a tecnológica, a militar, a legal, a cultural e a ambiental, com diferentes modelos de relacionamento. É possível distinguir diferentes formas históricas da globalização por meio da avaliação da extensão das redes de relações e conexões, da intensidade dos fluxos e dos níveis de atividade dentro dessas redes e do impacto desses fenômenos em comunidades particulares. Sob tal ótica, diversos regimes de ordem pessoal e de controle direto, com seus problemas e incertezas, cederam espaço a novas formas transnacionais de organização e de atividade, marcadas mais frequentemente por sistemas anônimos de poder, que começaram a se desenvolver independentemente dos Estados-nação nos quais se iniciaram. Em vez de impérios territoriais que submetem inúmeras regiões a um único sistema político, começou a se desenvolver uma ordem global fundamentalmente interconectada, marcada por densos modelos de troca, mas também pelo poder, pela hierarquia e pela desigualdade (HELD \& MCGREW, 2000).

A expansão da mídia por meio das novas tecnologias difundidas com a globalização operou numa dimensão simbólica de ligações entre o homem e as relações internacionais, disseminando uma iconografia popular que liga as masculinidades ocidentais a um mundo mais amplo além das fronteiras do Estado. As aventuras em terras estrangeiras aparecem ligadas à virilidade, de forma que elementos como a diplomacia, a espionagem e as atividades de líderes de Estado contribuíram para definir masculinidades hegemônicas no imaginário popular, como os mitos de heroísmo em torno de personagens como James Bond e sua ligação com um ideal aristocrático e cavalheiro da condição de homem ou de figuras reais ou fictícias como presidentes e primeirosministros vistos em posições decisórias importantes sobre os rumos da política internacional em noticiários de televisão ou mesmo no cinema. Os meios de comunicação oferecem uma fonte contínua de inspiração e de imaginação que informam o sentido dessas práticas e que definem uma rede de significados culturais nas quais as relações internacionais estão inseridas (HOPPER, 2001, p.87-88).

Ao mesmo tempo, a mídia também foi um ator fundamental no processo de difusão de novos papéis sociais, inclusive os relacionados às masculinidades. As masculinidades hegemônicas organizadas em torno do heroísmo da violência foram perdendo espaço após a Segunda Guerra Mundial, de forma a cederem mais espaço a noções ligadas à racionalidade tecnocrática, a meritocracia burguesa, a competitividade e a confiança num mundo corporativo, inseridas na expansão do liberalismo após a década de 1970. Além disso, a feminização da força de trabalho - que, em diversos Estados, minou a autoridade masculina na família e reduziu o valor de atributos masculinos hegemônicos no mercado (CONNELL, 1995) - e o fortalecimento dos movimentos feminista e LGBT estimularam transformações na representação das masculinidades hegemônicas e abriram espaço para maior desenvolvimento e expressão das subordinadas. Ademais, segundo Ribeiro \& Siqueira (2007), novas 
representações na forma de 'masculinidades subalternas ocidentais' - 'indivíduos do sexo masculino que se mostram pouco vinculados às práticas $\mathrm{e}$ discursos considerados próprios aos homens de uma dada sociedade' - vêm sendo disseminadas no processo de globalização. É possível incluir em tal categoria citada por Ribeiro \& Siqueira (2007) as diversidades das masculinidades gays desenvolvidas atualmente, que ganham mais visibilidade com o alcance global da música, da moda e de outras formas de produção artística e cultural e com a ampliação do conhecimento político-social e o debate sobre causas LGBT na mídia por militantes, políticos e artistas. Esses últimos, inclusive, tiveram papel importante na promoção de maior conhecimento e difusão da cultura gay e de suas formas de masculinidade, bem como suas causas políticas. Referências a tal cultura são visíveis, por exemplo, nas obras de cantoras como Madonna profunda articuladora do referencial simbólico masculino do mundo gay na sua produção artística e defensora de longa data das causas LGBT - e Lady Gaga - fenômeno da música pop da última década que se engajou politicamente em causas LGBT, como a oposição à legislação do 'Don't ask, don't tell', que impedia que aqueles que demonstrassem 'propensão para tentar praticar ou envolver-se em atos homossexuais' prestassem serviço nas Forças Armadas dos EUA. Dentre as novas formas de masculinidade, podem-se incluir também as heterossexuais alternativas contidas nos conceitos de metrossexualidade - conceito que remete a homens urbanos excessivamente preocupados com a aparência, característica tipicamente feminina na sociedade ocidental - e uberssexualidade - homens preocupados com aparência, mas sem o exagero dos metrossexuais.

Kimmel (1997) lembra que os significados da masculinidade não são fixos ou dados e assumem caráter contextual, podendo variar de acordo com a cultura e ao longo do tempo para cada ser humano. Porém, as múltiplas transformações do conceito de masculinidade - bem como outros conceitos ligados ao aparato de exclusão e de marginalização da diferença no nível internacional - não necessariamente supuseram sua superação como ideal regulador moderno, mesmo num contexto de reconfiguração dos contornos globais. Walker $(2005$, p.1) ressalta que, apesar da desestabilização gradativa de inúmeras segmentações no processo de globalização, as fronteiras artificiais, mesmo que não permaneçam onde estavam, ainda demarcam antagonismos. No caso, mesmo a difusão de concepções mais flexíveis de masculinidade a partir de referenciais ocidentais continuaria reproduzindo a exclusão e a marginalização de outros entendimentos cultural e temporalmente distintos do conceito, consolidando hierarquias mesmo que proponha maior abertura a visões alternativas as masculinidades hegemônicas ocidentais. Além disso, a ordem neoliberal pautada também numa política de heteronormatividade produz e reproduz a prevalência da heterossexualidade normativa, intimamente ligada às masculinidades hegemônicas na relação entre gênero e sexualidade. A reprodução heteronormativa das identidades permite a manutenção de uma visão neoliberal específica da atividade econômica, que é simultaneamente masculinizada e etnocêntrica, e normaliza a heterossexualidade como universal. Tal procedimento faz com que corpos funcionem por meio de fronteiras discursivas heterossexualizadas que são essencializadas e não-problematizadas, de forma a marginalizar a apagar a discussão sobre sexualidade e categorias de gênero da agenda do discurso econômico (GRIFFIN, 2007, p.221). Griffin (2007, p.222-225) argumenta que o discurso neoliberal - que, na verdade, é historicamente condicionado e orientado pelo poder - monopoliza o senso comum e regula as identidades com pressuposições não-questionadas sobre entendimentos específicos de 'democracia', 'liberdade' e 'autodeterminação'. As relações hierárquicas de gênero são reproduzidas a partir do mecanismo da heteronormatividade, que faz com que a heterossexualidade seja vista não somente como coerente, mas privilegiada. As oposições relegaram em segundo plano outras expressões da própria masculinidade, e a 'matriz heterossexual' na construção do homo economicus é mantida (GRIFFIN, 2007, p.235).

No próprio Ocidente, uma série de práticas disseminadas com as novas tecnologias por meio da globalização contribuiu para o reforço de masculinidades hegemônicas ocidentais, dentre as quais cabe citar a difusão da pornografia heterossexual pela internet, em relação à qual homens jovens demonstram atitudes bastante positivas (JOHANSSON \& HAMMARÉN, 2007, p.66). Segundo Fagan (2010), ao apresentar o acesso a práticas sexuais de forma ilimitada e o trazer como algo que não tem efeitos sobre emoções dos indivíduos, o cyberporn leva a percepções distorcidas da realidade social, em particular a uma percepção exagerada do nível da atividade sexual. Ademais, reitera a percepção de que os homens são guiados pelo sexo e de que as mulheres - e, no caso da pedofilia, também as crianças independentemente do sexo - são objetificadas sexualmente e descritas em termos sexuais em vez de seus outros atributos pessoais. No contexto da globalização, a internet produziu, de acordo com Garlick (2009, p.1-2, 11-15) ${ }^{2}$, uma mudança 
qualitativa na forma como seus espectadores são afetados pela pornografia: além de a tecnologia ampliar a habilidade do homem de controlar a experiência pornográfica e o corpo feminino, o cyberporn participa de uma narrativa maior de uma confrontação tecnológica entre o homem e a natureza, o que envolve diretamente o sentido das masculinidades hegemônicas, cuja base está na ideia do 'desejo de controle'. As masculinidades hegemônicas na imaginação pornográfica heterossexual definem um modelo de relação de gênero em que os homens se colocam em controle das mulheres e deles mesmos e seus corpos em geral aparecem como máquinas que funcionam com 'eficiência técnica'. A experiência de assistir a vídeos pornográficos - facilitada pela internet - oferece ao homem o sentido de confiança, aceitação e falta de ansiedade em comparação ao mundo do sexo fora da pornografia, no qual sua sexualidade é experimentada como não-problemática e não há o receio de 'perder o controle', já que as mulheres são representadas como sempre receptivas aos desejos sexuais do homem. Na visão de Garlick (2009, p.13-15), ao evocar uma natureza sexual 'primitiva' para domesticá-la no confinamento do corpo masculino mecanizado, a pornografia permite que a natureza seja colocada sob controle e canalizada para fins que servem à consolidação das masculinidades hegemônicas. A internet permite reforçar a promessa de controle tecnológico, além de que o cyberporn pode chegar a distâncias muito além de seus locais de produção.

Nesse contexto, Hirdman (2007, p.163-168) aponta que, com a divisão entre o público e o privado, a sexualização do corpo masculino heterossexual parece resultar na perda de sua heterossexualidade, ligando-o à feminização e ao homoerotismo. Assim, seu simbolismo visual nos filmes pornográficos difundidos pela internet fica predominantemente reduzido ao pênis - em geral grande e ereto -, que funciona como uma metáfora da sexualidade masculina e denota controle da linguagem, dos símbolos e do pensamento logocêntrico. A expressão facial do homem heterossexual em geral é deixada de lado nesses filmes e a imagem foca o 'corpo performático', em particular o órgão sexual, de forma que a expressão do desejo masculino não esteja significada na face, mas implicada na ação e na performance mecânica da sexualidade. Ela legitima o poder masculino baseado na supremacia corporal em relação à mulher. Ao mesmo tempo, operam outras hierarquias que reificam a posição superior das masculinidades hegemônicas brancas. Os corpos e os pênis de homens brancos parecem ser repositórios de mais do que um corpo e sim de um espírito, de forma que corpos de homens não-brancos parecem ser mais 'corpos' e menos 'espírito'. Outras masculinidades como a do homem heterossexual negro são limitadas na sua representação a simplesmente 'corpos', que podem até ter mais músculos ou pênis maiores, mas são concebidos como 'apenas corpos' hiper masculinizados. O padrão recorrente na pornografia heterossexual mantém a integridade das masculinidades hegemônicas brancas, que preserva a impressão de que esse homem branco é mestre de seus desejos corporais e é, assim, menos 'animalesco' que o homem heterossexual negro. Como aponta Fejes (2002, p.100-101), além da difusão da pornografia heterossexual masculina, a homossexual também se expandiu no contexto da globalização. Porém, de forma ainda mais intensa que o 'heteroporn', o 'gayporn' traz com mais frequência representações do desejo sexual masculino como uma expressão da violência e do poder, e a construção da identidade masculina gay e sua expressão em subculturas ainda aparecem baseadas em referenciais de dominação presentes numa masculinidade heterossexual, mas reconfigurados, tendo em vista que essa última repudia o desejo homoerótico dos homens.

\section{Aqui nasce 0 amor" confiança, intimidade e diálogo na recriação das masculinidades ocidentais}

Giddens (1992, p.131) afirma que os homens têm dificuldade de lidar com a igualdade, sendo marcados pela dinâmica de poder relacionada ao gênero e não se mostram capazes de amar os outros como iguais em circunstâncias de intimidade. Todavia, são, muitas vezes, capazes de oferecer amor e cuidado àqueles numa posição inferior de poder, que possam dominar e controlar. Eles se mostram por vezes incapazes de construir uma narrativa sobre eles mesmos que os permita harmonizar com uma esfera democrática e reordenada da vida pessoal. Como sinaliza Lorentzen (2007, p.192) ao falar especificamente dos homens heterossexuais e ainda presos aos referenciais das masculinidades hegemônicas, as ideias de amor e intimidade ainda estão ligadas às mulheres e aos gays. O que esse artigo revela é que a difusão da guerra e da violência no processo de expansão da ordem internacional e da globalização acirrou modelos hegemônicos e excludentes de masculinidade, impedindo efetivamente a conciliação de diferenças e a resolução de conflitos, quadro que acaba por promover mais intolerância e instabilidade no sistema político doméstico e internacional. Mais especificamente, os discursos político-sociais e culturais produzidos no contexto das relações 
internacionais são intensamente permeados por questões de gênero e revelam a consolidação das masculinidades hegemônicas, oferecendo respostas ao problema da legitimidade do patriarcado e sustentando a posição dominante primordialmente de homens heterossexuais brancos e a subordinação das feminilidades (RIBEIRO \& SIQUEIRA, 2007) e das masculinidades subordinadas. Nesse processo, aquilo que é associado à feminilidade, como as emoções individuais, é desvalorizado; assim, o gênero age como um meio de contenção de certas formas de pensamento, de ação e de discurso (ZALEWSKI \& ENLOE, 1995). Como aponta Steans (1997), essa dinâmica traz à tona a relação entre masculinidade, autoridade e violência tecnológica, que reafirma a inferioridade da experiência feminina e de masculinidades subalternas, destrói a tradição de nãoviolência e reforça a ligação entre militarismo e outras formas de dominação, como o sexismo. Tal processo estimula a perpetuação de hierarquias entre indivíduos e grupos e legitima a ideia de que a diferença deva ser subjugada ou eliminada no nível doméstico e no internacional.

Porém, há caminhos possíveis que sinalizam a superação e a transgressão dos modelos de poder patriarcal e a redefinição das formas de entendimento da diferença, abrindo a possibilidade para que sentimentos como o amor possam criar laços mais estáveis entre iguais e diferentes e desestabilizem rivalidades numa ética de reconhecimento da diferença e de compartilhamento de valores para a resolução pacífica de disputas e controvérsias. A desestabilização da ideia de uma suposta incapacidade do homem heterossexual de amar iguais - ideia essa amplamente difundida pelas noções de masculinidade hegemônica - pode ser promovida a partir de uma análise mais cuidadosa das relações entre esses iguais, como nas relações afetivas entre pai e filho, irmãos ou amigos (Lorentzen, 2007, p.195-197). A exploração da intimidade nessas relações por meio do compartilhamento de experiências e da construção da confiança pode representar um primeiro passo, na ampliação da capacidade desse homem heterossexual de conviver e, de até mesmo, amar os iguais e transformar o perfil de relação que ele desenvolve com os diferentes. Como argumenta Lorentzen (2007, p.197), o amor traz meios para a transgressão de fronteiras culturais entre e sobre os homens e permite a criação de novas formas de masculinidade. $\mathrm{O}$ foco no amor não inclui automaticamente idealização ou defesa das tradicionais masculinidades hegemônicas e a perda de vista sobre as perspectivas críticas. O amor como transgressão sinaliza para uma mudança do sistema de gênero que inclui o potencial radical dos homens para entender, repensar e se transformar.

No contato com as diferenças em relação as masculinidades hegemônicas - em particular com as feminilidades e as masculinidades subordinadas -, as relações internacionais podem ter papel importante na redefinição das perspectivas de interação, especialmente com as possibilidades abertas pela globalização ao permitir o contato e a troca de informações e criar zonas de contato mais intensas com a diferença. Porém, é na exploração de possibilidades alternativas dessas zonas em relação às que ainda temos hoje onde pode estar à chave para uma transformação mais profunda. $\mathrm{O}$ que se propõe aqui é uma reimaginação crítica do perfil das relações internacionais como relações intersociais e interculturais a partir de uma perspectiva etnológica. A diferença seria concebida como um recurso de autoavaliação capaz de transformar visões do $\mathrm{Eu}$ com relação ao Outro e à sua própria cultura no 'momento etnológico' todoroviano, e o diálogo sociocultural poderia permitir a desestabilização de tendências polarizantes que objetificam a diferença. Tal iniciativa proporcionaria respostas aos desafios da interação com a diversidade por meio da autorreflexão crítica, do compartilhamento de experiências e de críticas à opressão e à exclusão visando à sua superação no pensamento e na prática e da aliança entre críticas sociais culturalmente diversas à desigualdade, indo na direção oposta do movimento de equação entre diferença e inferioridade. Defendo, com base em Blaney \& Inayatullah (2004, p.7-17), que, a partir do aprendizado no tratamento das ambiguidades geradas na interação com a diferença em relação ao gênero, do reconhecimento da diversidade e da exploração das possibilidades alternativas das 'zonas de contato' psicológico e social, o diálogo potencial colabora para a elucidação das culturas e das relações de gênero nos níveis doméstico e internacional e estabelece o contato entre tradições que respondem à marginalização gerada no processo de reprodução das masculinidades hegemônicas ocidentais. São recuperadas vozes recessivas na interpretação do contexto histórico, desessencializados os entendimentos dominantes e estabelecido o vínculo entre tradições recessivas na própria identidade e as demais culturas a fim de se oferecer uma visão de libertação em relação à opressão para $\mathrm{Eu}$ e Outro na dinâmica de sua reimaginação e sua recriação.

1 Hugo Grotius, por exemplo, buscava bases não-problematizadas para uma ordem civil capaz de implementar a justiça natural e, embora refutasse um 
direito generalizado de violenta perseguição religiosa, não defendia proteção a dissidentes religiosos em face das necessidades políticas e oferecia justificativas para a violência no subjugo de não-europeus no processo de colonização. Na base da preservação do 'bem público' como princípio regulador, John Locke sugere que soberanos apliquem punições aos 'incapazes' de seguir um padrão de sociedade baseado na propriedade e no comércio e defende pragmaticamente uma visão circunstancial de tolerância pela impossibilidade de se constituir uniformidade em questões religiosas de forma coercitiva e a conformidade cultural fortalecida pela sanção político-social, além de vislumbrar um mundo partido em Estados territoriais 'civilizados', a usurpação das terras indígenas e a assimilação dos ameríndios aos padrões da sociedade civil europeia (BLANEY \& INAYATULLAH, 2004, p.35-43).1

2 Segunda publicação no v. 12, n. 5, p. 597 614, August 2010.

\section{Referências}

BLANEY, David L.; INAYATULLAH, Naeem. International Relations and the problem of difference. Nova York: Routledge, 2004.

BRITTON, Dana M.; WILLIAMS, Christine L. Don't Ask, Don't Tell, Don't Pursue: Military Policy and the Construction of Heterosexual Masculinity. Journal of Homosexuality, v.30, n.1, p.1 - 21, 1995.

CHRISTENSEN, Wendy M.; FERREE, Myra Marx. Cowboy of the World? Gender Discourse and the Iraq War Debate. Qualitative Sociology, n.31, p. 287 - 306, 2008.

CONNELL, R. W. Masculinities. Cambridge: Polity Press, 1995.

DARBY, Phillip. The fiction of imperialism: reading between international relations and postcolonialism. Londres; Washington, D.C.: Cassell, 1998.

FAGAN, Patrick F. The Effects of Pornography on Individuals, Marriage, Family and Community. Family North Carolina Magazine, inverno 2010. [Disponível em: <http://www.ncfpc.org/FNC/1001SF.html> Acesso em: 27 de dezembro de 2010.]

FEJES, Fred. Bent passions: heterosexual masculinity, pornography, and male gay identity. Sexuality \& Culture, v.6, n.3, p. 95 - 113, jul. 2002.
GARLICK, Steve. Taking Control of Sex? Hegemonic Masculinity, Technology, and Internet Pornography. Men and Masculinities, v. 0, n.0, p.1$18,2009$.

GIDDENS, Anthony. The Transformation of Intimacy. Cambridge: Polity Press, 1992.

GRIFFIN, Penny. Sexing the Economy in a Neoliberal World Order: Neo-liberal Discourse and the (Re)Production of Heteronormative Heterosexuality. British Journal of Politics \& International Relations, v. 9, n. 2, p. $220-238,2007$.

HELD, David; MCGREW, Anthony. Prós e contras da globalização. Rio de Janeiro: Jorge Zahar Editor, 2000 .

HINOJOSA, Ramon. Doing hegemony: military, men, and constructing a hegemonic masculinity. The Journal of Men's Studies, v. 18, n. 2, p.179 - 194, primavera 2010.

HIRDMAN, Anja. (In)Visibility and the Display of Gendered Desire: Masculinity in Mainstream Soft and Hardcore Pornography. Nordic Journal of Women's Studies, v. 15, n. 2-3, p. 158 - 171, jun./set. 2007.

HOOPER, Charlotte. Manly states: Masculinities, International Relations, and Gender Politics. Nova York: Columbia University Press, 2001.

IKENBERRY, G. John. Varieties of order: balance of power, hegemonic, and constitutional. In: IKENBERRY, G. John. After victory: institutions, strategic restraint, and the rebuilding of order after major wars. Princeton: Princeton University Press, 2000. p. 21 - 49.

JOLL, James. Imperialism. In: JOLL, James.. Europe since 1870: an international history. 2. ed. Harmondsworth, Midd.: Penguin Books, 1976, p. 78 112 .

JOHANSSON, Thomas; HAMMARÉN, Nils. Hegemonic Masculinity and Pornography: Young people's attitudes toward and relations to pornography. The Journal of Men's Studies, v. 15, n. 1, p. 57 - 70, inverno 2007.

KEENE, Edward. Beyond the anarchical society: Grotius, colonialism and order in world politics. Cambridge; Nova York, NY : Cambridge University 
Aqui J az o Amor: 0 nascimento do homem, a produção

das masculinidades e as relações internacionais

Press, 2002.

KIMMEL, Michael S. Homofobia, temor, vergüenza y silencio en la identidad masculina. In: VALDÉS, T.; OLIVARIA, J. (Ed.). Masculinidade/s: poder $\mathbf{y}$ crisis. Santiago, Chile: Isis Ediciones de las mujeres/FRACSO, 1997, p. 49 - 62.

LORENTZEN, Jorgen. Love and Intimacy in Men's Lives. Nordic Journal of Women's Studies, v. 15, n. $2-3$, p. $190-198$, jun./set. 2007.

MANKAYI, Nyameka. Masculinity, sexuality and the body of male soldiers. PINS, n. 36, p. 24 - 44, 2008.

NYE, Robert A. Western Masculinities in War and Peace. American Historical Review, v. 112, n. 2, p. 418 - 438, abr. 2007.

RIBEIRO, Claudia Regina; SIQUEIRA, Vera Helena Ferraz de. O novo homem na mídia: ressignificações por homens docentes. Revista Estudos Feministas, v. 15, n. 1, abr. 2007. [Disponível em: $<$ http://www.scielo.br/scielo.php?script=sci_arttext\&pi $\mathrm{d}=$ S0104-026X2007000100013\&lng=en\&nrm=iso $>$ Acesso em 18 dezembro de 2009]

STEANS, Jill. Gender and international relations: an introduction. Cambridge: Polity Press, 1997.

STOLCKE, Verena. O enigma das interseções: classe, 'raça', sexo, sexualidade: a formação dos impérios transatlânticos do século XVI ao XIX. Revista Estudos Feministas, v. 14, n. 1, abr. 2006. [Disponível em: $<$ http://www.scielo.br/scielo.php?script=sci_arttext\&pi $\mathrm{d}=\mathrm{S} 0104-026 \mathrm{X} 2006000100003 \& \operatorname{lng}=$ en\&nrm=iso $>$ Acesso em18 dezembro de 2009]

WALKER, R.B.J. The doubled outsides of the Modern International. 5th International Conference on Diversity in Organizations, Communities and Nations. C.a.N. Fifth International Conference on Diversity in Organizations. Beijing, June 30 - July 3 , 2005.

ZALEWSKI, Marysia; ENLOE, Cynthia. Questions about identity in International Relations. In: BOOTH, Ken; SMITH, Steve. (Org). International Relations Theory Today. University Park: The Pennsylvania University Press, 1995, p. 279 - 305.

Recebido em 12 de janeiro de 2011. Aceito em 18 de julho de 2011. 